\title{
Forever amber on manipulating DNA molecules?
}

LAST weekend saw a hundred scientists descending on Oxford to discuss with representatives of the Research Councils and the Department of Health and Social Security the problems of experimentation in the 'genetic engineering' field. It is now six months since the Ashby report was published and gave what we described at the time as an amber light to such experiments. The Ashby working party took evidence from more than twenty workers or potential workers in this field, but was itself constituted of scientists who in the main did not include those using the techniques and who might therefore have had a direct interest in the conclusions. Ashby reported that "subject to rigorous safeguards [spelt out in the report] these techniques should continue to be used because of the great benefits to which they may lead". But how to implement these safeguards, and how to implement them quickly?

Several participants were at pains to point out the intellectual pressure that is building up to get moving again in this field. It was wrily conceded that more impatient scientists were already under way and although there was no evidence that they were conducting experiments in an irresponsible way, their action was causing considerable frustration amongst those waiting for more formal guidance on safety. It is, as one participant put it, rather like the vivisection laws-until society has spoken it is left to the vagaries of individual consciences. And there is obvious pressure to go aheadparticipants, on being asked whether they, as individuals, would wish to perform such experiments within the next two years, said 'yes' in considerable numbers.

If the issue were as simple as that, then the most obvious course would be to place as much pressure as possible on the Department of Education and Science, with whom the Ashby report now resides, to get cracking and persuade the government, amidst all its obsessions with consensus in inflation-control to give a moment's thought to the consensus in hazard-control, and implement the safeguards. (The meeting overwhelmingly endorsed the Ashby recommendations on strict containment.) But there are complicating factors.

First, the consensus amongst scientists that all could be made and kept safe is no longer accepted as the watertight guarantee that it once would have been. There has been a certain amount of self-satisfaction that where- as the Asilomar conference was a meeting of those with a direct interest in the experiments, the Ashby report came from those who could take a broader view. But broad enough? Technicians have an obvious interest in safety, and their concern, expressed through their union, will not necessarily mesh with the scientists' desire to get moving as soon as possible. The pharmaceutical and agricultural industries, barely represented in the Ashby testimony, may at some time in the future wish to switch from laboratory to large-scale operations; they have an obvious interest in ensuring that the safeguards in any legislation make sense on the larger scale. And what about members of the public? Ashby went out of its way to ask 'how can the social values of the community at large be incorporated into decisions on science-policy?', and tried to present the report in a widely-accessible form. But how can the government assess what the community feels on this subject?

Second, there is doubt in some scientists' minds about the scope of any proposed code of practice. There was clear agreement at Oxford that Ashby and Godber should not be confused - that is, that there should be a difference in governmental approach towards the as yet unpredictable hazards of artificial recombinant DNA molecules and the predictable hazards of pathogens with their established handling procedures. But how openended should the discussion on unpredictable hazards be left? Some believe that the dangers in currently-known methods may seem slight in comparison with the dangers in methods only dimly foreseen. On the other hand, to widen the debate, the administrators in particular believe, would be to diminish the chances of a quick response from the government.

It may not be an issue of great substance but we feel that the exclusion of the scientific press from the Oxford meeting was unfortunate. We hardly believe that any dark conspiracies were hatched, but there is broader interest amongst scientists in this issue than in almost any other at present, and since one of the purposes of the meeting was to inform and educate, it should be said that an informed and educated press ought to have been one of the (admittedly lesser) aims of the organisers. It is difficult to accept the argument that participants would speak less freely with the press on hand, when there were already a hundred pairs of ears around. 